IOSR Journal of Engineering

Mar. 2012, Vol. 2(3) pp: 478-483

\title{
Choosing an Appropriate ERP Implementation Strategy
}

\author{
Kamal Khanna ${ }^{1}$, Gazal Preet Arneja ${ }^{2}$ \\ ( ${ }^{1}$ Department of Mechanical Engineering, Shaheed Bhagat Singh College of Engineering \& Technology, \{Poly Wing\} \\ Ferozepur-152004) \\ $\left({ }^{2}\right.$ Principal, Shaheed Bhagat Singh College of Engineering \& Technology, \\ \{Poly Wing\} Ferozepur-152004)
}

\begin{abstract}
Although ERP implementation has evolved certain years back but still the industries hesitate to deploy it in their structure since it is unquestionably an intricate task. The hesitation will itself results in the mission of successful implementation to go in vain. It become challenging for many industries to deploy ERP in their projects as many reports of complete and partial failures enlightened the implementation of ERP software packages as a hard-hitting task. The prospect can be set for the successful implementation of an ERP system by controlling and minimizing the major business risks at the preliminary stage by selecting the appropriate strategy that determines how the ERP system should be deployed. These strategies focus on how to switch over from the old legacy system to new ERP system in an efficient manner. This paper explains the relationship of ERP transition strategies between the three basic risks; people, process and technology and thus aid the ERP implementers to better recognize what type or combination of strategies will suit their system the best.
\end{abstract}

Keywords: Big-Bang, Enterprise Resource Planning, ERP Implementation Strategy, Hybrid, Parallel, Project

\section{Introduction}

Selecting an appropriate ERP implementation strategy is not something that should be came up to without a great deal of planning and proper execution. In choosing a new enterprise resource planning (ERP) software, implementation is as important as finding the right program. Every one should be thinking about it proactively when evaluating systems \& should raise the topic with prospective vendors and even ask for examples of their customers' strategies [6]. There are hundreds of articles on "best practices" for implementing ERP software, but understanding each strategy and choosing the best option is difficult [1]. So, we set out to consolidate the information in a single guide. Our aim is to give enough information - and the most important pieces to choose the best implementation process for every organization. Moving forward to an ERP software selection process, now armed with ERP strategy, industries have a higher probability of success with their enterprise system selection, one that is a good fit with business. The cost of an ERP project initiative is significant attributed with the cost of the software and the expense of getting the software installed and in use [7]. Implementation costs can easily surpass the cost of the ERP software application many times over, so measures to moderate implementation costs, such as a solid ERP strategy; can have significant cost saving impacts that can dramatically increase the projects ROI (Return on Investment).

I. Organizational Change Issues. First, this approach creates organizational change management issues. On the one hand, this approach helps create buy-in and ownership of the new system. However, ERP change is significant enough as it is, so going live without having worked through at least the major issues can be disruptive and demoralizing to the average employee. In addition, users become very frustrated when their system changes from week to week due to new enhancements or updates to the system.

II. Business Risk. The organization that was profiled was an educational institution, and the ERP focus was on financial functionality. The article notes that there were problems processing paychecks as a result of going live without hashing out all the kinks. One could argue that a few missed paychecks aren't too big of a deal, but the consequences could be much more severe for a manufacturing or distribution industry that finds it can only ship a fraction of its normal volume after go-live [3]. If we were the CEO of a manufacturing or distribution industry, there is no chance of being comfortable with this approach given the high level of business risk and uncertainty around this style of implementation.

III. Lack of Clear Requirements and Functionality. There is something to be said for drawing a line in the sand and saying that we won't go-live with the new system until key business requirements and functions are fully developed and tested. Going live without ensuring that key business needs are met may be harmful for project.

IV. Difficulty: Managing System Changes. The flexibility of ERP makes a more iterative approach more possible; software can constantly be changed as needed to meet evolving business requirements. However, such flexibility can create somewhat of an operational mess if not managed appropriately prior to and after going-live. 
IOSR Journal of Engineering

Mar. 2012, Vol. 2(3) pp: 478-483

The factors that could cause an industry to choose one ERP strategy over other are: technical resource availability, number of users, consultant availability, structure of ERP team, deadlines, reliability and hardware resources.

\section{ERP Implementation Transition Strategies}

An ERP implementation strategy determines how the ERP system will be installed. Different industries may install the same ERP software in totally different processes [6]. The same industry may implement different software in the same approach.

There are several transition strategies but most of them are variants of the five basic types:
a) Big Bang
b) Phased
c) Parallel
d) Process Line
e) Hybrid

These techniques focus on the strategy of how to make the transition from a legacy system to a new ERP system. ERP implementations all begin with the simple question- how do we make the transition from our inheritance ERP system to new ERP system? The selection of the transition strategy that is best suited for each industry is crucial as a wrong strategy can result in a failed or flawed implementation. Three pillars-people, process and technology are the base of any ERP implementation. Failure to use one of these or failure to use it in the best possible manner can result in failure. Understanding the relationships of ERP transition strategies between the process, people, and technology will assist the ERP implementers to better understand what type or combination of types of ERP transition strategy is best.

I. Big Bang Transition Strategy: In this strategy industries layout a magnificent map for their ERP implementation. The installation of ERP systems of all modules happens across the entire organization at once. The big bang approach promised to reduce the integration cost in the condition of thorough and careful execution. This method dominated early ERP implementations and it partially contributed to the higher rate of failure in ERP implementation. All the business functions performed in the inheritance system across the entire enterprise are concurrently transferred to the new legacy system during a period of one day or a weekend. But now a day's industries are wavering to use big bang approach as it consumes too many resources to support the go-live of the ERP system. Success in using the big bang approach comes with careful preparation and planning prior to using big bang. But many industries struggle to decide whether the big bang approach is the right selection or not for their endeavor.

\begin{tabular}{|l|c|}
\hline \multicolumn{1}{|c|}{ Legacy System } & \multicolumn{2}{c|}{$\begin{array}{c}\text { Go- Live } \\
\text { Date }\end{array}$} \\
\hline Past & Future \\
\hline Finance & Finance \\
\hline Manufacturing & Manufacturing \\
\hline Human Resources & Human Resources \\
\hline Materials Management & Materials Management \\
\hline Quality Management & Quality Management \\
\hline Plant Maintenance & Plant Maintenance \\
\hline Marketing & Sales and Distribution \\
\hline Sales and Distribution & \\
\hline
\end{tabular}

Figure 1 -Big Bang ERP Transition Strategy (Source: Leon. A, 2009) 
II. Phased Transition Strategy: The phased approach, implements one practical element at a time, in chronological order as shown in fig. Autonomous modules of ERP systems are installed in each unit, while integration of ERP modules is done at later stage of the project. This has been the most commonly used method of ERP implementation. Each business unit may have its own "instances" of ERP and database. Modular (phased) implementation reduces the risk of the installation, customization and operation of ERP systems by reducing the scope of the implementation. The unbeaten implementation of one module can help the overall success of an ERP project. The interface programs that are used in this strategy bridge the gap between the inheritance ERP system and the new ERP system until the new ERP system becomes fully purposeful. This strategy is often used in situations that not have strong centralized synchronization in the ERP project.

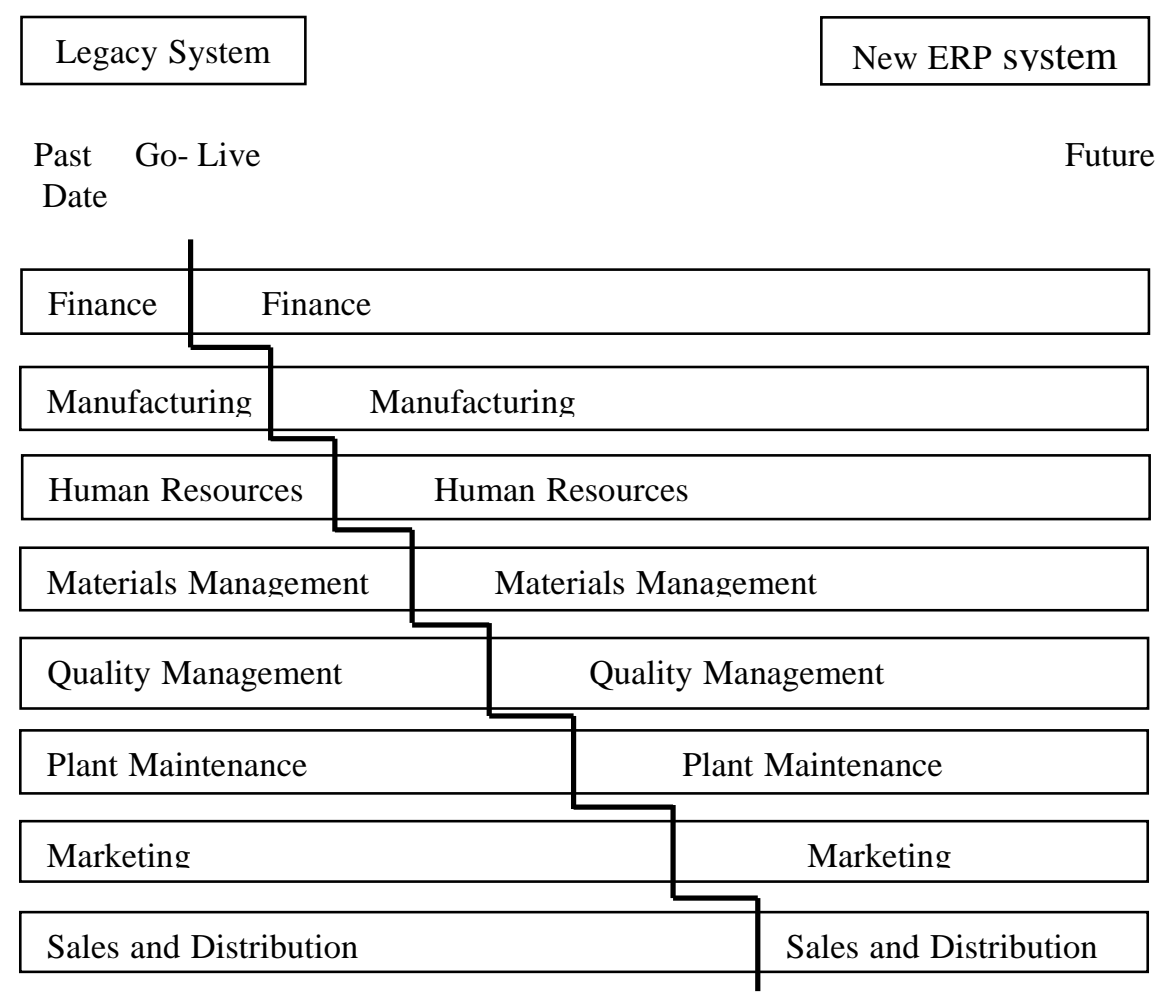

Figure 2 -Phased ERP Transition Strategy (Source: Leon. A, 2009)

III. Parallel Transition Strategy: The parallel approach keeps both the inheritance system and the new ERP system active concurrently for a length of time as shown in fig. The amount of time for which both the systems are in operation ranges from one day to several months and may be to years. Portions of the same functional business areas (including software) such as finance, manufacturing, marketing etc. are operating at the same time for both the legacy and ERP systems. An advantage to the parallel strategy is that it has good improvement options in case something goes off beam. Because both the inheritance ERP system and the new ERP system are in function at the same time for a particular module, the industry's business processes will not be broken up if the new ERP system breakdowns. The parallel approach also provides the most sensible number-to-number comparisons to authenticate that the new ERP system is performing the necessary business process flows. This strategy is ideally suited for mission critical situations that cannot survive a major break down of an ERP system. 
IOSR Journal of Engineering

Mar. 2012, Vol. 2(3) pp: 478-483

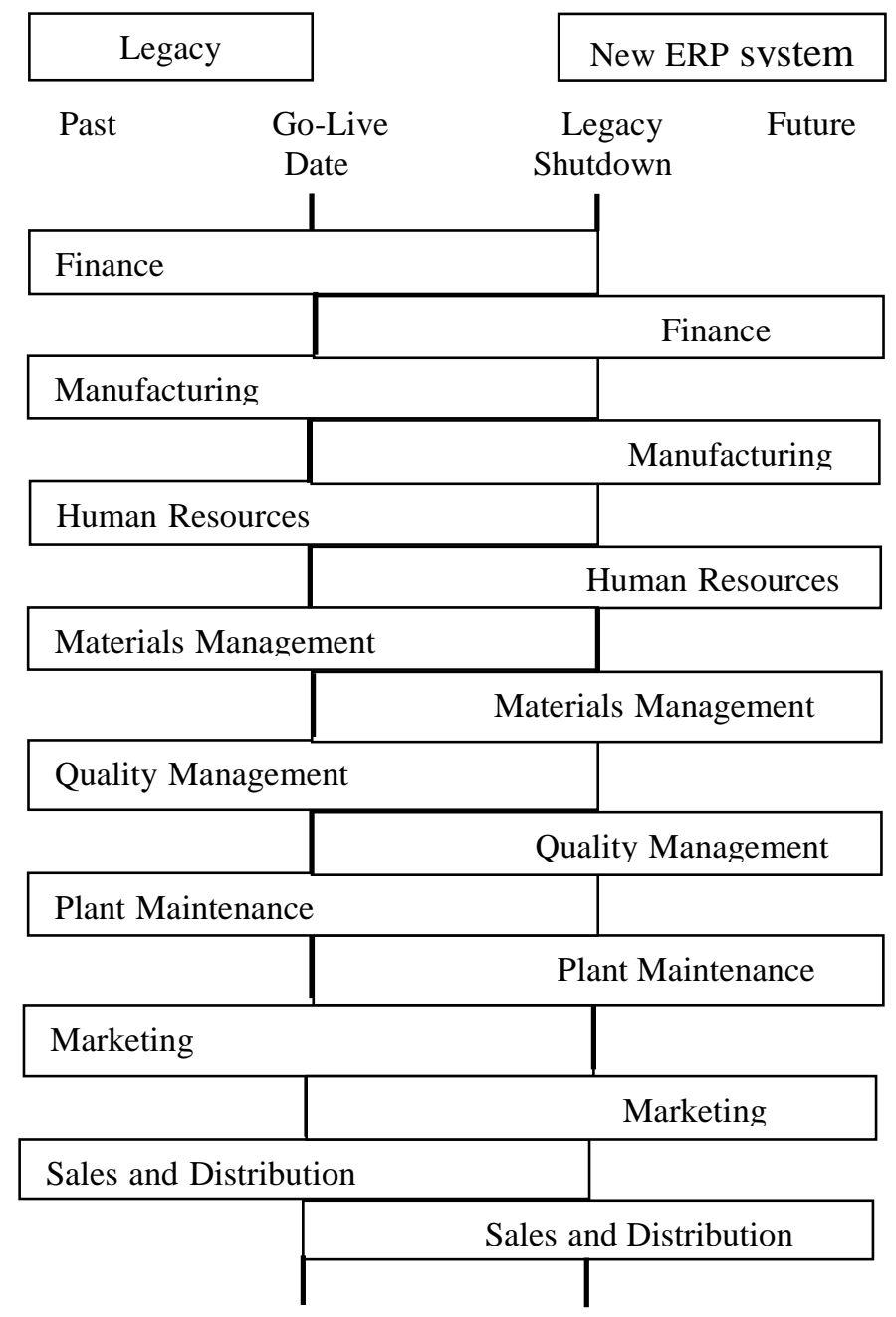

Figure 3 -Parallel ERP Transition Strategy (Source: Leon. A, 2009)

IV. Process Line Transition Strategy: The process line transition strategy breaks the implementation strategy to handle similar business process flows or product lines. Using the process line strategy, the first product line and related assets go first in making the transition from the inheritance system to the new ERP system. Once this transition is achieved successfully, the second product line is moved from the inheritance system to the new system. This initial success helps to build industrial faith in the new ERP system, increasing its overall prospect of success. Upon achievement of the first process line, resources are loaned to the more complicated and challenging process lines. 
IOSR Journal of Engineering

Mar. 2012, Vol. 2(3) pp: 478-483

\begin{tabular}{|l|}
\hline Old Svstem-1 \\
\hline Old Svstem-2 \\
\hline
\end{tabular}

\begin{tabular}{|c|c|c|}
\hline Past & & Future \\
\hline Finance & \multicolumn{2}{|c|}{ Finance } \\
\hline \multicolumn{2}{|c|}{ Finance } & Finance \\
\hline Manufacturing & \multicolumn{2}{|c|}{ Manufacturing } \\
\hline \multicolumn{2}{|c|}{ Manufacturing } & Manufacturing \\
\hline Human Resources & \multicolumn{2}{|c|}{ Human Resources } \\
\hline \multicolumn{2}{|c|}{ Human Resources } & Human Resources \\
\hline Materials Management & \multicolumn{2}{|c|}{ Materials Management } \\
\hline \multicolumn{2}{|c|}{ Materials Management } & Materials Management \\
\hline Quality Management & \multicolumn{2}{|c|}{ Quality Management } \\
\hline \multicolumn{2}{|c|}{ Quality Management } & Quality Management \\
\hline Plant Maintenance & \multicolumn{2}{|c|}{ Plant Maintenance } \\
\hline \multicolumn{2}{|c|}{ Plant Maintenance } & Plant Maintenance \\
\hline Marketing & \multicolumn{2}{|c|}{ Marketing } \\
\hline \multicolumn{2}{|c|}{ Marketing } & Marketing \\
\hline Sales and Distribution & \multicolumn{2}{|c|}{ Sales and Distribution } \\
\hline \multicolumn{2}{|c|}{ Sales and Distribution } & Sales and Distribution \\
\hline
\end{tabular}

Figure 4 -Process Line ERP Transition Strategy (Source: Leon. A, 2009)

V. Hybrid Transition Strategy: It is the combination of any of the implementation strategy like process line, phasing and parallel implementation strategy. Hybrid strategies tend to evolve into the needed agreement as ERP team members study and consider information. The complexity of a hybrid strategy varies tremendously depending upon the state. Small single-site ERP implementations tend to have simpler hybrid strategies than those used by large conglomerate corporations with many dissimilar environmental locations. Many implementations use hybrid strategies because they are flexible in adapting to the specific needs of the situation. With the hybrid strategy, industries can exclusively adjust implementations for their needs.

\section{Conclusion}

It can be concluded that if somebody is the ERP coordinator then he/ she must ensure to build the time factor into the enterprise's road map. Make sure that senior management should understand the commitment ERP will require. ERP implementation is not a by-the-way project. It is concluded that ERP implementation is a journey and not the final destination and hence an implementation strategy must be selected according to the needs of the particular industry and not just showing to the world. If all the plans of transition will go right then specific business and business processes are aligned anyone can see dramatic positive impacts on ROI (Return on Investment). This dramatically improved ROI benefit; ERP software vendors will most likely to configure what are considered the best practices in their industry in the ERP solution to create a more seamless and speedier implementation through the proper selection of an ERP implementation strategy. ERP vendors should make a strong effort to show company's how to reduce their implementation costs with their systems by having a well thought out ERP strategy and communication process. In an economic slumps its understandable why 
IOSR Journal of Engineering

Mar. 2012, Vol. 2(3) pp: 478-483

initiatives to lower costs are high on the list of priorities for industries all over the globe. Costs savings are the name of the game for every department, cost center and every nook and cranny across the entire organization.

\section{4. $\quad$ References}

1. Thomas H. Davenport, "Putting the Enterprise into the Enterprise system" Harvard Business Review, 121-131(1998).

2. Holland, P., Light, B. and Gibson, N. "A critical success factors model for enterprise resource planning implementation", Proceedings of the 7th European Conference on Information Systems (1), 273-97, (1999).

3. Thomas H. Davenport and Harris, "Mission Critical - Realizing the Promise of Enterprise Systems" Harvard Business school publishing, (2000).

4. M.L. Markus, C. Tanis, P.C. van Fenema, "Multisite ERP implementations, Communications of the ACM" 43 (4) (2000) 42-46.

5. Liang-Chuan Wu, Chorng-Shyong Ong, Yao-Wen Hsu, “Active ERP implementation management: A Real Options perspective" The Journal of Systems and Software (81) 2008, pp. 1039-1050.

6. Leon, A., "Enterprise Resource Planning”, Tata McGraw-Hill, INDIA, 2009.

7. Wincel, J.P “Lean Supply Chain Management”, R.M. Donovan Inc. \& Co.2010.

8. Sumner, M., "Enterprise Resource Planning”, Prentice Hall, 2004.

9. http://www.erp.com

10. http://www.erpandmore.com 